\title{
Optimization of Inner Dumping Uncovered Height with Partially Covered End Wall in Adjacent Surface Coal Mining Districts
}

\author{
Li Ma $\mathbb{D}^{1,2}$ Zhiguo Chang $\mathbb{D},{ }^{3,4}$ Kemin Li $\mathbb{D}{ }^{3}$ Shuangshuang Xiao $\mathbb{D}^{1},{ }^{1}$ and Xiaohua Ding $\mathbb{D}^{3}$ \\ ${ }^{1}$ School of Energy Engineering, Xian University of Science and Technology, Xian, Shaanxi 710054, China \\ ${ }^{2}$ State Key Laboratory for Geomechanics \& Deep Underground Engineering, China University of Mining and Technology, \\ Xuzhou, Jiangsu 221116, China \\ ${ }^{3}$ School of Mines, China University of Mining and Technology, Xuzhou, Jiangsu 221116, China \\ ${ }^{4}$ Department of Mining, Xinjiang Institute of Engineering, Urumqi, Xinjiang 830000, China
}

Correspondence should be addressed to Li Ma; mali21786@hotmail.com and Zhiguo Chang; changzg@cumt.edu.cn

Received 14 April 2017; Accepted 27 July 2017; Published 3 January 2018

Academic Editor: Anna M. Gil-Lafuente

Copyright (C) $2018 \mathrm{Li} \mathrm{Ma}$ et al. This is an open access article distributed under the Creative Commons Attribution License, which permits unrestricted use, distribution, and reproduction in any medium, provided the original work is properly cited.

In order to analyze the relationships of inner dumping with covered end wall in adjacent surface coal mining districts, a troughshaped uncovered end wall model was put forward. A mathematical model concerning uncovered end wall height (UEWH) was established based on minimum cost method. The inner dump capacity was considered regarding its effect on UEWH. Besides, a comprehensive model was established for calculating optimal UEWH in inner dumping with partially covered end wall mode and a shifting distance optimization model based on cost compensation method for building a provisional haulage system to connect inner dump. As for case study in Huolinhe number 1 surface coal mine, research results show that optimal UEWH was $225 \mathrm{~m}$ between North Pit and South Pit whereas in number 3 mining district of North Open-Pit Mine it was $23.50 \mathrm{~m}$ when making its transition from cross mining to mining along strike. Nevertheless, due to limited inner dump capacity, inner dump height in South and North mining districts shall be appropriately increased and closed pits from earlier period shall be fully utilized to make room for inner dumping with partially uncovered end walls.

\section{Introduction}

In order to enlarge the economic benefits in early stage and during the entire service period of mining, nearly horizontal and slowly inclined coalfields suitable for surface mining are normally divided into several mining districts. These mining districts are then excavated one by one in accordance with deposit occurrence and the prevailing technical and economic conditions. But in normal cases, inner dumping with the covered end wall in the previous mining district would bring about increased amounts of restripping, resulting in secondary stripping cost when excavating the next mining district $[1,2]$. Therefore, proper transition and mutual influence among mining districts have become the main problem facing nearly horizontal surface coal mines [3-5]. Under these circumstances, the mode of inner dumping with partially covered end wall has proven to be an effective solution that brings about the best economic benefits in comparison with other surface coal mining engineering practices [6-8]. Figure 1 illustrates several basic modes of inner dumping with covered end walls. To be specific, when the end wall is fully covered by stripped overburden, it is called "entirely covered end wall" (as shown in Figure 1(a)). When the internally dumped materials are transported to a designated place which would later become the end wall for the next mining district, the dumped materials would form a construction body in the gob area, and this mode is named "uncovered end wall entirely" (as shown in Figure 1(b)). The condition where the end wall is not entirely covered by overburden material is called "partially covered end wall" (as shown in Figure 1(c)). 


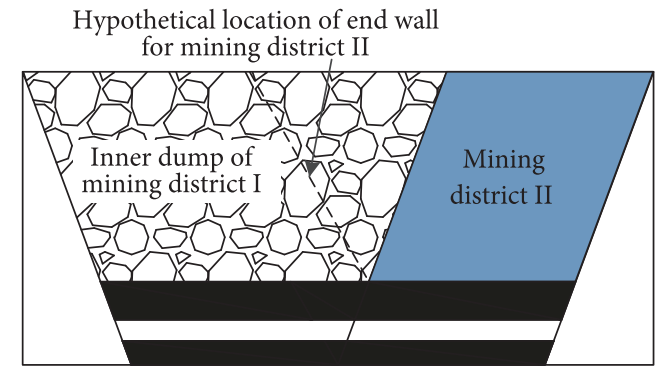

(a) Entirely covered end wall

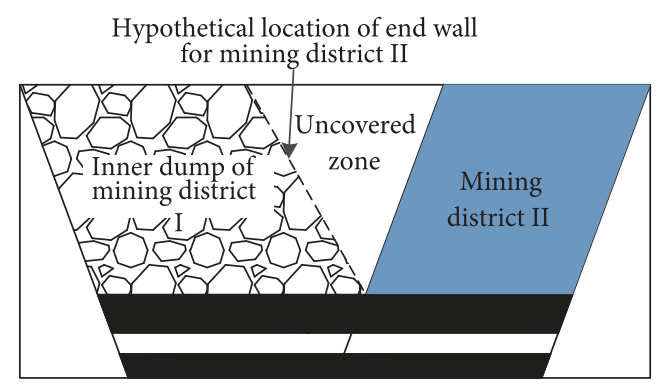

(b) Uncovered end wall entirely

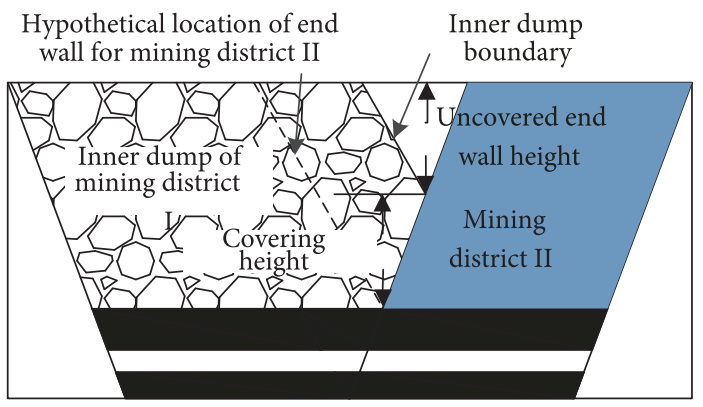

(c) Partially covered end wall

FIGURE 1: Basic modes of inner dump covering in surface coal mines.

By definition, if an end wall is entirely covered, the stripped materials from the previous mining area would be dumped into the mined-out area with the entire end wall covered. Therefore, when the next mining area is excavated, those materials need to be restripped and dumped again which brings about increased stripping costs [9]. Whereas in the case of entirely uncovered end wall, the end wall of the next mining district is assured to be uncovered as the stripped-out overburden is transported to other spots thereby increasing inner dump height. However, the disadvantage of this mode lies in the fact that it would cause extra costs when transferring materials from the uncovered zone. [10]. Besides, since the connection between end wall and inner dump is removed by the existing of uncovered zone, the original round transport corridor becomes one-way corridor as the haulage system on the other side remains unchanged, and this increases transportation cost as well. Hence, as a combination of the above two modes, the mode of inner dumping with partially covered end wall is the most cost effective solution of the three. Its economic advantage is closely related to the height of the uncovered end wall.

Regarding UEWH in this mode, Gu and Zha (1996) conducted an analysis about the correlation of covering height of the end wall (EWCH) with working face length and the end wall angle of repetitive stripping and restripping time. Based on these analyses, they obtained an optimum EWCH range under different conditions using minimum relevant cost method [11]. Zhou et al. (2009) analyzed factors that may influence EWCH in inner dumping and coal mining practice. By establishing the calculation model of $\mathrm{EWCH}$, they determined that the mining depth, the open-pit bottom width, and end wall slope angle play the most influential role in this

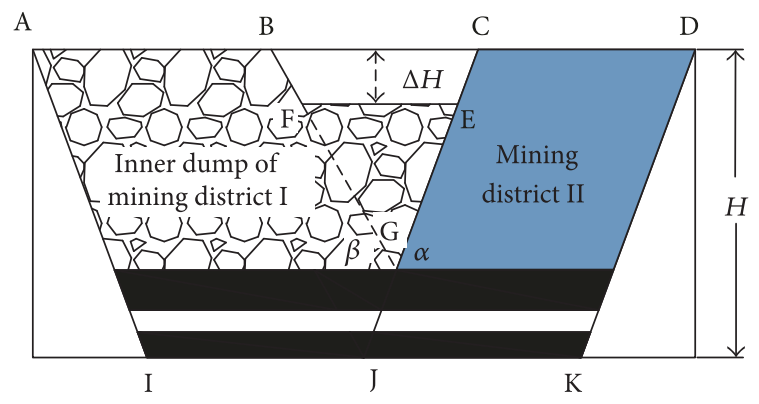

Figure 2: Trough-shaped uncovered section.

regard [12]. In addition, Zhao et al. (2012) explored respective characteristics of the entirely covered end wall, entirely uncovered end wall, and partially covered end wall modes in nearly horizontal surface coal mining and inner dumping practices. They further established economic benefit models on the basis of the uncovered end wall height [13]. Liu et al. (2015) built an EWCH optimization model according to transport distance features by adopting the expense compensation method [14]. Obviously, according to existing study results in this regard, an inverted triangular covered end wall mode is the only mode that has ever been taken into account, as illustrated in Figure 1(c). As a matter of fact, there are two basic principles in determining UEWH: (1) reducing restripping amount and (2) reducing the number of transportation system levels affected by reserving uncovered area. On the basis of these two principles, a trough-shaped level uncovered mode has been presented in this paper, as shown in Figure 2. When the uncovered area is the same, the UEWH 


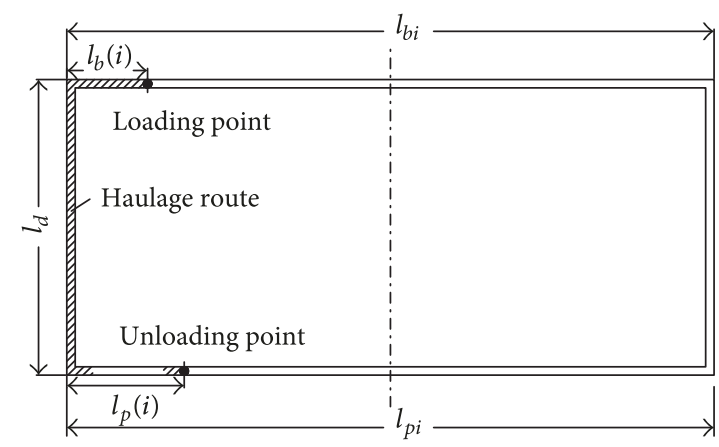

(a) Round inner dumping corridor

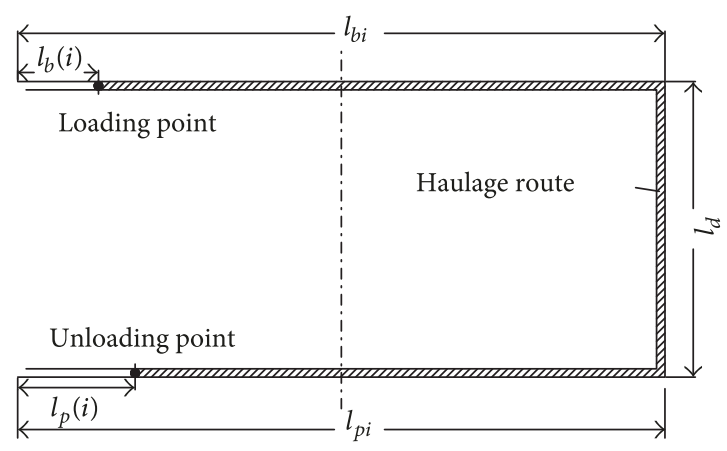

(b) One-way inner dumping corridor

FIGURE 3: Round inner dumping corridor versus one-way inner dumping corridor.

of a trough-shaped mode is smaller than that of an inverted triangular mode. That would translate into a lesser number of influenced end wall transportation systems levels when restripping amount is the same. In this sense, a trough-shaped level uncovered mode is more advantageous to an inverted triangular mode when it comes to the transition of the mining area. Hence, a trough-shaped level uncovered mode is thoroughly analyzed here in the article. A mathematical model about the optimization of UEWH is also established so as to realize integrated EWCH optimization of inner dumping in the case of adjacent mining transition districts.

\section{Mathematical Model for Optimizing UEWH of Inner Dumping with Partially Covered End Wall}

\subsection{Determination of UEWH Based on \\ Minimum Comprehensive Costs among \\ Adjacent Mining Districts}

2.1.1. Restripping and Transferring Costs Influenced by Uncovered Zone Capacity. According to the geometric relationships between the partially covered end wall and the entirely covered end wall shown in Figure 2, we have

$$
\begin{aligned}
S & =S_{w}-S_{h}, \\
S_{w} & =\frac{H^{2}}{2}(\cot \alpha+\cot \beta), \\
S_{h} & =\frac{(H-\Delta H)^{2}}{2}(\cot \alpha+\cot \beta),
\end{aligned}
$$

where $S$ is the area of uncovered end wall, $\mathrm{m}^{2} ; S_{w}$ is the restripping area in the case of entirely covered end wall, $\mathrm{m}^{2}$; $\alpha$ is the final end wall slope angle of the entity slope, $\circ ; \beta$ is the final end wall slope angle of the restripped slope, $\circ ; H$ is mining depth of the open pit, $\mathrm{m} ; S_{h}$ is the restripping area in the case of uncovered end wall, $\mathrm{m}^{2} ; \Delta H$ is the depth of uncovered zone, $\mathrm{m}$.
From (1), the area of the uncovered zone would be obtained as

$$
S=\left(H \Delta H-\frac{\Delta H^{2}}{2}\right)(\cot \alpha+\cot \beta) .
$$

As a result of the uncovered end wall, the reduced restripping cost per year and the annually increased cost as a result of purchasing external dumping sites and transporting the stripped materials would be expressed as

$$
\begin{aligned}
& C_{1}=S \cdot a \cdot A \\
& C_{2}=S \cdot a \cdot B,
\end{aligned}
$$

where $C_{1}$ is the annual restripping cost, RMB/a; $a$ is the annual advancing distance rate of the surface coal mine, $\mathrm{m} / \mathrm{a}$; $A$ is the unit restripping cost, $\mathrm{RMB} / \mathrm{m}^{3} ; C_{2}$ is the annually increased cost as a result of purchasing external dumping sites and transporting the stripped materials, $\mathrm{RMB} / \mathrm{a} ; B$ is the unit increased cost for purchasing an external dumping site and increasing haul distance, $\mathrm{RMB} / \mathrm{m}^{3}$;

\subsubsection{Haul Distance and Transportation Cost Changes Affected} by Uncovered End Wall. Due to the influence of inner dumping with partially covered end wall, round transport corridor (using end wall berms on both sides for overburden haulage and dumping) may continue to be used for dumping stripped overburdens for rock stripping benches below bottom level elevation, whereas, for those end wall rock stripping benches above bottom level elevation and adjacent to the next mining district, the only option would be a one-way transport corridor (namely, only one-sided end wall berm could be used for overburden haulage and dumping), since they are not connected to the inner dump as shown in Figure 3.

Generally speaking, in the case of using round inner dumping corridor, the stripped-out overburdens on the left side of working face would be delivered to the corresponding dumping site via the left end wall and it is likewise for the stripped-out overburdens on the right side of working face. When it comes to a one-way inner dumping, haulage system 


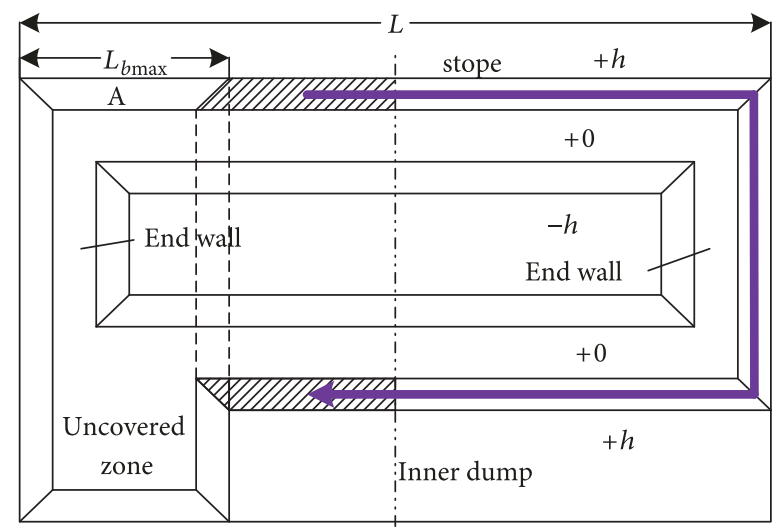

Haulage direction for overburden materials

FIGURE 4: One-way inner dumping diagram with partially covered end wall.

of overburden removal would be influenced on either left or right side of a working face. Hence, the respective one-way and round overburden haulage distance would be expressed as

$$
\begin{aligned}
& L_{1}(i)=l_{b}(i)+l_{p}(i)+l_{d}, \\
& L_{2}(i)=\left[l_{b i}-l_{b}(i)\right]+\left[l_{p i}-l_{p}(i)\right]+l_{d},
\end{aligned}
$$

where $L_{1}(i)$ is the round overburden haulage distance from the $i$ th level stripping bench to inner dump, $\mathrm{m} ; L_{2}(i)$ is the one-way overburden haulage distance from the $i$ th level stripping bench to inner dump, $\mathrm{m} ; l_{b}(i)$ is the haulage distance from the loading point on the $i$ th level stripping bench to the nearest end wall, $\mathrm{m} ; l_{p}(i)$ is the haulage distance from the end wall of the $i$ th level dumping bench to the dumping site, $\mathrm{m} ; l_{d}$ is the haulage distance along end wall, $\mathrm{m}$.

According to follow-up working characteristics in the dumping with excavating mode, the stripped overburden would be internally dumped onto the bench on the same level. Assume the stripping working line is as long as the dumping working face; namely, $l_{b i}=l_{p i}=l_{i}$; then the increased haulage distance in the case of using a one-way corridor (in comparison with using round corridor) would be expressed as

$$
\Delta L_{i}=L_{2}(i)-L_{1}(i)=2\left[l_{i}-2 l_{b}(i)\right]
$$

Taking half of the UEWH as the centre of stripped overburdens, then the length of the stripping working face of this level is

$$
L=l+(2 H-\Delta H) \cot \alpha,
$$

where $l$ is the horizontal length at pit bottom, $\mathrm{m}$.

Theoretically speaking, the haulage distance from the loading point on the stripping bench to the nearest end wall should not be more than half the length of stripping working face and also not less than the uncovered width on the same levelled dumping bench. As shown in Figure 4, the shaded part represents the stripping amount that would be influenced in the case of using a one-way inner dumping corridor; hence, the average increased haulage distance in comparison with round transport would be expressed as

$$
\begin{aligned}
\Delta L & =\frac{2\left(L-2 L_{b \max }\right)+2(L-2 \cdot L / 2)}{2}=L-2 L_{b \max } \\
& =l-(2 H-\Delta H) \cot \beta .
\end{aligned}
$$

The corresponding annually increased haulage distance and increased costs resulting from a one-way haulage would be expressed as

$$
\begin{aligned}
Q & =\frac{a \cdot[l-(2 H-\Delta H) \cot \beta] \cdot \Delta H}{2}, \\
C_{3} & =\frac{Q \cdot \Delta L \cdot \gamma_{b} \cdot C}{1000},
\end{aligned}
$$

where $C_{3}$ is the annual increase in cost value resulting from one-way haulage, RMB; $\gamma_{b}$ is the average bulk weight of stripped materials, $\mathrm{t} / \mathrm{m}^{3}$; and $C$ is the truck freight per ton per kilometre, $\mathrm{RMB} / \mathrm{t} \cdot \mathrm{km}$.

Similarly, when the next mining district is under exploitation, a one-way inner dumping corridor would also be applied to working benches above the uncovered zone. The corresponding increased cost is

$$
C_{4}=\frac{Q^{\prime} \cdot \Delta L^{\prime} \cdot \gamma^{\prime} \cdot C^{\prime}}{1000}
$$

where $C_{4}, Q^{\prime}, \Delta L^{\prime}, \gamma^{\prime}, C^{\prime}$ represent the corresponding indicator for a one-way inner dumping in the next mining district, respectively.

\subsubsection{Integrated Optimization of UEWH Based on Minimum} Cost Method. There exist time differences regarding coal mining and inner dumping engineering in adjacent mining districts. Therefore, according to the time value of capital theory, $C_{1}$ and $C_{4}$ are converted to present value for calculation, and the total benefits would be obtained as follows:

$$
J=C_{1}(1+\rho)^{-n}-C_{2}-C_{3}-C_{4}(1+\rho)^{-n},
$$

where $J$ represents the overall economic benefits generated by using the mode of inner dumping with partially covered end wall, $\mathrm{RMB} ; \rho$ is the bank interest rate, \%.

Inserting (7), (8), and (9) into (10), the following cubic function concerning the overall economic benefits and the uncovered depth is obtained:

$$
\begin{aligned}
& J=I_{1} \Delta H^{3}+I_{2} \Delta H^{2}+I_{3} \Delta H, \\
& I_{1}=-\left[\frac{a \cdot \gamma_{b} \cdot C}{2}+\frac{a \cdot \gamma_{b} \cdot C}{2}(1+\rho)^{-n}\right] \cot ^{2} \beta,
\end{aligned}
$$




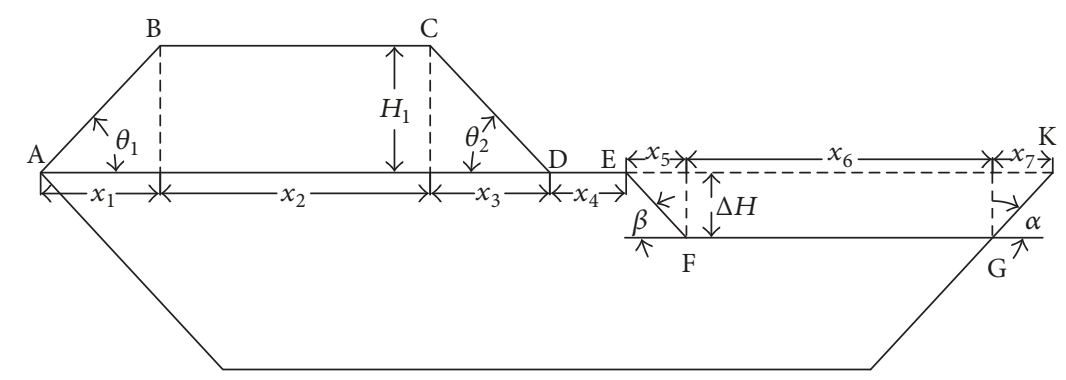

FIGURE 5: Schematic diagram of inner dump capacity versus uncovered end wall height.

$$
\begin{aligned}
I_{2}= & -2(l-2 H \cot \beta) \\
& \cdot\left[\frac{a \cdot \gamma_{b} \cdot C}{2}+\frac{a \cdot \gamma_{b} \cdot C}{2}(1+\rho)^{-n}\right] \cot \beta \\
& -\frac{1}{2}(\cot \alpha+\cot \beta) a\left[A(1+\rho)^{-n}-B\right], \\
I_{3} & =\left[\frac{a \cdot \gamma_{b} \cdot C}{2}+\frac{a \cdot \gamma_{b} \cdot C}{2}(1+\rho)^{-n}\right](l-2 H \cot \beta)^{2} \\
& +H(\cot \alpha+\cot \beta) a\left[A(1+\rho)^{-n}-B\right] .
\end{aligned}
$$

On the basis of (11), the derivative of $J$ on $\Delta H$ is obtained as

$$
\frac{d J}{d(\Delta H)}=3 I_{1} \Delta H^{2}+2 I_{2} \Delta H+I_{3} .
$$

Assuming that $d J / d(\Delta H)=0$, the two roots $\Delta H_{1}, \Delta H_{2}$ from (12) should be given by

$$
\Delta H=\frac{-2 I_{2} \pm \sqrt{4 I_{2}^{2}-12 I_{1} I_{3}}}{6 I_{1}} .
$$

The above roots could help identify the monotonicity of three intervals, namely, $\left(-\infty, \Delta H_{1}\right),\left[\Delta H_{1}, \Delta H_{2}\right)$, and $\left[\Delta H_{2},+\infty\right)$. For UEWH not greater than the open-pit mining depth, the interval of UEWH would be confined to $[0, H]$. In other words, the corresponding abscissa for the UEWH extremum within the interval $[0, H]$ would be the optimum UEWH $\Delta H_{\text {cal }}$ in the mode of inner dumping with partially covered end wall.

2.2. Inner Dump Capacity Constraint on UEWH. When part of the end wall remains uncovered in the inner dump, the capacity of inner dump would be reduced. However, the situation could be modified by increasing the height of overburden pilings up in the covered area of the inner dump. Therefore, when considering the UEWH, it has to be guaranteed that the inner dumping space that has been extended to its extreme is able to accommodate the remaining overburden amounts resulting from the partially uncovered end wall.

The cross-sectional area $S_{1}$ of extended dumping space (namely, the ABCD area in Figure 5) and the cross-sectional area $S_{2}$ of non-dumpable space resulting from the partially uncovered end wall, respectively (namely, the EFGK area in Figure 5), should be given as

$$
\begin{aligned}
& S_{1}=x_{2} \cdot H_{1}+\frac{H_{1}^{2}}{2 \tan \theta_{1}}+\frac{H_{1}^{2}}{2 \tan \theta_{2}}, \\
& S_{2}=x_{6} \cdot \Delta H+\frac{\Delta H^{2}}{2 \tan \beta}+\frac{\Delta H^{2}}{2 \tan \alpha},
\end{aligned}
$$

where $x_{2}$ is the horizontal length of the top of inner dump, $\mathrm{m} ; \theta_{1}$ and $\theta_{2}$ are slope stability angles of inner dump, $\circ H_{1}$ is the extended height of the inner dump, $\mathrm{m} ; x_{6}$ is the bottom width of uncovered area in the inner dump, $\mathrm{m} ; \beta$ is the slope angle of the uncovered area, $\circ ; \alpha$ is the ultimate slope angle of the end wall of the entire slope, $\circ ; \Delta H$ is UEWH, $\mathrm{m}$.

When considering the extended inner dumping space and capacity, the surplus inner dumping space in the case of entirely covered end wall has to be taken into account as well; namely,

$$
S_{1} \cdot a+\Delta Q \geq S_{2} \cdot a,
$$

where $\Delta Q$ is the surplus inner dumping space when the end wall is entirely covered, $\mathrm{m}^{3}$. Negative $\Delta Q$ means inadequate inner dumping space while positive $\Delta Q$ means surplus inner dumping space, which may compliment the non-dumpable space as a result of partially uncovered end wall

$$
\begin{aligned}
\Delta H \leq & \Delta H_{\max } \\
= & \sqrt{\frac{2\left(S_{1}+\Delta Q / a\right) \tan \beta \tan \alpha}{\tan \beta+\tan \alpha}+\left(\frac{\tan \beta \tan \alpha}{\tan \beta+\tan \alpha}\right)^{2}} \\
& -\frac{x_{6} \tan \beta \tan \alpha}{\tan \beta+\tan \alpha} .
\end{aligned}
$$

To sum up, two factors have been taken into account in determining the partially uncovered end wall height in the case of inner dumping. One is the influence that inner dumping and end wall covering practices exert on the comprehensive economic benefits in adjacent mining districts. The other factor is the inner dump capacity constraint. Here in this article, increased non-dumpable amount problem resulting from partially covered end wall is alleviated solely by increasing the height of inner dump instead of using any 


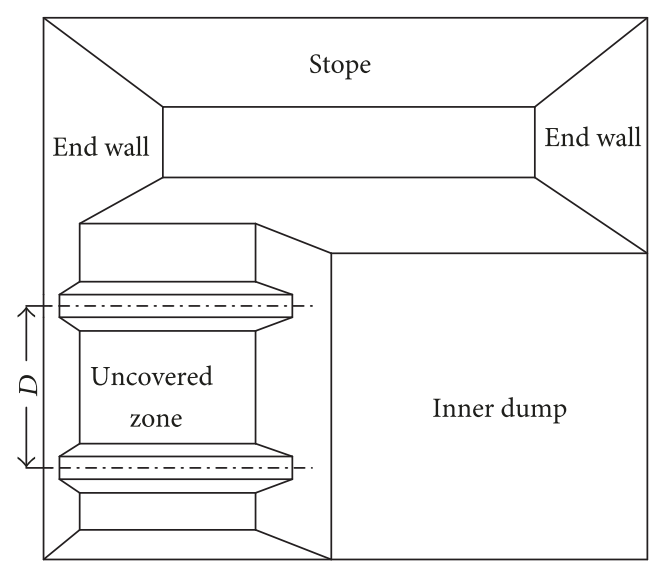

FIGURE 6: Schematic diagram of building PHP in the mode of inner dumping with partially uncovered end wall.

external dumping site. In this case, the UEWH shall be given by

$$
\Delta H=\min \left\{\Delta H_{\text {cal }}, \Delta H_{\max }\right\}
$$

\section{Shifting Distance Optimization Based on Expense Compensation Method in the Case of Building Provisional Haulage Pathway (PHP) to Connect Inner Dump}

To reduce the effects of one-way haulage method on transport costs, a PHP could be built using the stripped overburden as a transport pathway to connect the uncovered end wall and the inner dump working face, as shown in Figure 6.

PHP shifting distance is one of the important factors that affect the economic benefits of the inner dumping practice. Specifically, the larger the shifting distance, the lower the expenses resulting from PHP building and repeated overburden stripping. On the other hand, trucks have to cover greater haulage distance between the end wall and dumping site to deliver the stripped materials, bringing about increased transportation costs. Therefore, the optimum PHP shifting distance has to be determined by comparing with a one-way haulage distance. The equivalent one-way haulage distance is defined as the sum of the increased haulage distance resulting from vehicles' climbing up and down the slope as well as increased PHP shifting distance, which should be expressed by

$$
L_{r}=2 \frac{H(i)}{R} C_{q}+D,
$$

where $L_{r}$ is the equivalent one-way haulage distance, $\mathrm{m}$; $H(i)$ is the altitude difference between the centre of gravity of the $i$ th bench and the PHP level, $\mathrm{m}$; $R$ is road limiting gradient which is generally $8 \%-10 \%, \circ ; C_{q}$ is coefficient of road extension line; $D$ is the PHP shifting distance, $\mathrm{m}$;

A basic principle is that the equivalent one-way haulage distance should not be greater than the increased distance from truck's one-way transport corridor; namely, $L_{r} \leq \Delta L$.
Hence, based on this principle and by combining (7) and (18), the following equation is obtained:

$$
2 \frac{H(i)}{R} C_{q}+D \leq l-(2 H-\Delta H) \cot \beta .
$$

And the upper limit of the shifting distance would be further given by

$$
D \leq l-(2 H-\Delta H) \cot \beta-2 \frac{H(i)}{R} C_{q} .
$$

Since the transportation cost saved as a consequence of PHP building should not be lower than the restripping cost for the back filling materials used for PHP building, the following expression is obtained:

$$
\begin{aligned}
& C_{5} \geq C_{6}, \\
& C_{5} \\
& =\frac{\left[l-(2 H-\Delta H) \cot \beta-2(H(i) / R) C_{q}-D\right] Q C \gamma}{1000}, \\
& C_{6}=A V_{q} \frac{a}{D},
\end{aligned}
$$

where $C_{5}$ is the transportation costs saved as a consequence of PHP building, RMB; $C_{6}$ is the restripping cost for the backfilling materials used for PHP building, RMB; $V_{q}$ is the PHP volume, $\mathrm{m}^{3}$.

In this case, the lower limit of shifting distance will be given by

$$
\begin{aligned}
& D \\
& \geq \frac{1000 A V_{q} a}{\left[l-(2 H-\Delta H) \cot \beta-2(H(i) / R) C_{q}-D\right] Q C \gamma} .
\end{aligned}
$$

The reasonable scope of PHP shifting distance would hence be given by combining (20) and (22); namely,

$$
\begin{gathered}
\frac{1000 A V_{q} a}{\left[l-(2 H-\Delta H) \cot \beta-2(H(i) / R) C_{q}-D\right] Q C \gamma} \\
\quad \leq D \leq l-(2 H-\Delta H) \cot \beta-2 \frac{H(i)}{R} C_{q} .
\end{gathered}
$$

\section{Case Study}

4.1. Production Conditions in Huolinhe Number 1 Surface Coal Mine. Huolinhe number 1 surface coal mine is $10 \mathrm{~km}$ long from north to south and $3.4 \mathrm{~km}$ wide from east to west. It has a surface area of $34 \mathrm{~km}^{2}$ and mining depth ranging from $864 \mathrm{~m}$ to $432 \mathrm{~m}$ elevation. Its coal seam runs in the direction of northeast-southwest and it is reclining towards northwest. Coal seam dip angle is no more than 10 degrees $[15,16]$. Huolinhe number 1 surface coal mine has been divided into South Open-Pit Mine (SOPM) and North Open-Pit Mine (NOPM) for respective excavation, as shown in Figure 7. Specifically, three mining districts in SOPM have reached the 


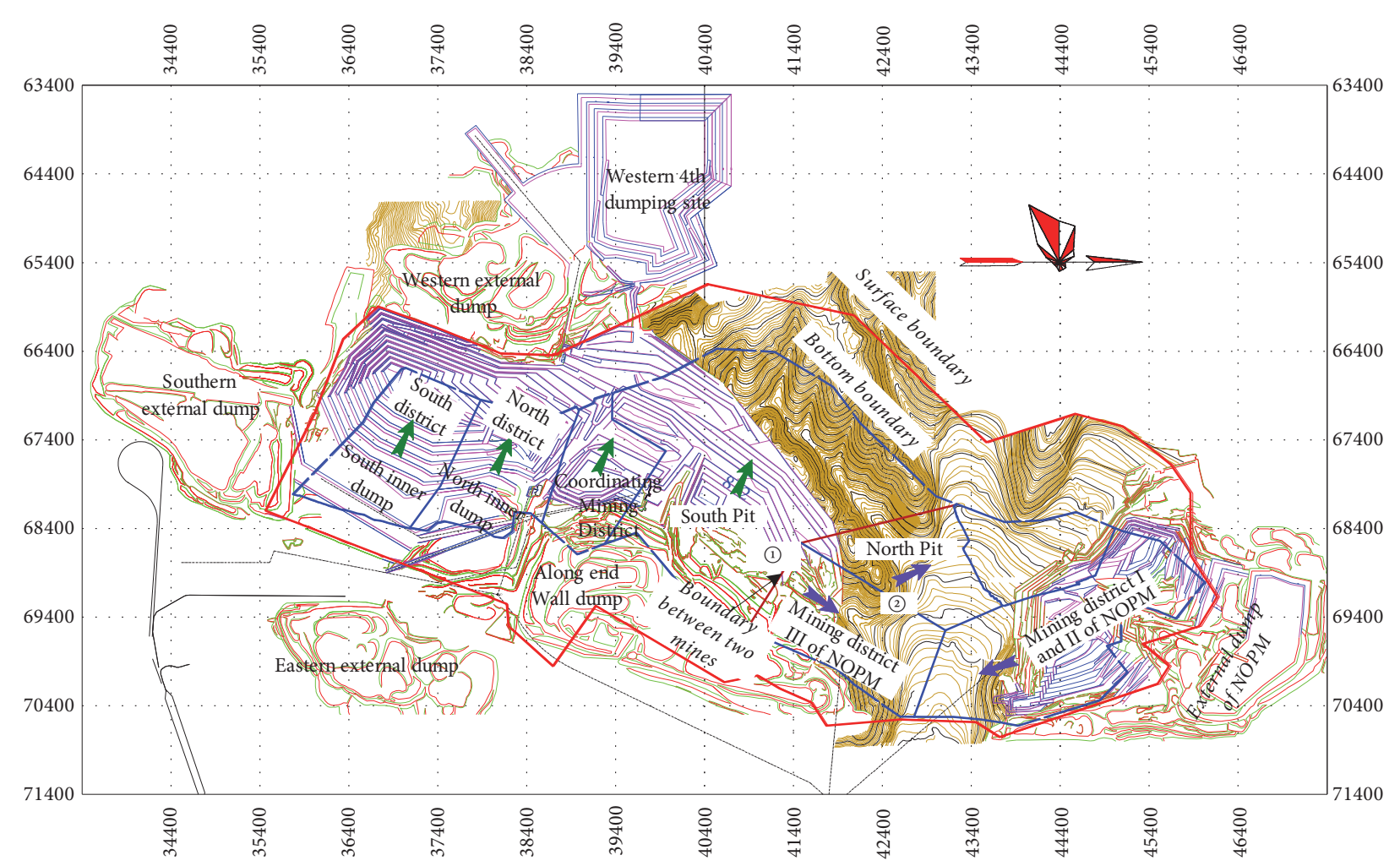

FIGURE 7: Uncovered end wall position plan between open pits and mining districts.

end of their excavation, namely, the South District, North District, and Coordinating Mining District. As for the rest of the coalfield that remains unexploited, it has been divided as South Pit for further mining. SOPM has nine minable coal seams, numbered, respectively, as 6 \#, 8 \#, 10 \#, 11 \#, 14 \#, 17 \#, 19 \#, 21 \#, and 24 \# coal seam, of which 10 \#, 14 \#, 17 \#, and 21 \# coal seams are the main minable ones. When it comes to the overburden stripping in SOPM, the processes adopted include single bucket, truck technology and single bucket, truck, semifixed crushing station, belt conveyor, and overburden spreader. As for NOPM, in addition to number 1 , number 2, and number 3 mining districts that are currently under excavation, the rest of the coalfield that remains unexploited has been divided as North Pit for further mining. According to the mining procedure in North Pit, number 3 mining district advances northwards while number 1 and number 2 mining districts advance southwards. Once their working faces converge, it would result in mining along strike pushing westward. NOPM has 8 minable coal seams, namely, 8 \#, 10 \#, 11 \#, 14 \#, 17 \#, 19 \#, 21 \#, and 24 \# coal seams, of which 14 \#, 19 \#, and 21 \# are the main ones. The overburden stripping practice in the NOPM adopts a single bucket-truck system.

At present, SOPM has five external dumps and two inner dumps. Among the external dumps, the eastern, the southern, the western, and the one along the end wall have reached their upper limit of dumping capacity and the remaining capacity in the western 4 th dumping site is 75 million $\mathrm{m}^{3}$. The dumping capacity in South Inner Dump and
North Inner Dump is, respectively, 707.227 million $\mathrm{m}^{3}$ and 999.015 million $\mathrm{m}^{3}$. As to NOPM, it contains one external dump and one inner dump and their respective capacity is 17.006 million $\mathrm{m}^{3}$ and 25.975 million $\mathrm{m}^{3}$.

When the South Pit and North Pit advance in a parallel direction, their common end wall would be repeatedly covered. And there would also be interaction problem when number 3 mining district of NOPM makes a transition from cross mining to mining along strike. In this case, two modes of uncovered end walls have been put forward to solve these two problems. The first mode and solution is inner dumping with partially covered end wall between SOPM and NOPM. The other one is slow slope and partially uncovered end wall transition mode in adjacent mining districts. Figure 7 (1) and (2)) is an illustration of these two modes and the UEWH has been optimized, respectively.

4.2. Comprehensive Determination of UEWH. According to the uncovered end wall position in between open pits and mining districts, the relevant parameters are shown in Table 1.

According to (13), the optimization model of optimal UEWH and the monotonicity of the function in (11) which concerns economic benefits and UEWH would be determined.

(1) Between South Pit and North Pit, in the case of $\Delta H \in(-\infty,-31.28]$ and $\Delta H \in(225,+\infty), J$ is a decreasing function, whereas, in the case of $\Delta H \in(-31.28,225], J$ is an increasing function. Actually, within the interval $[0,350]$ and when $\Delta H=225, J$ reaches its maximum value. 
TABLE 1: Relevant parameters in between open pits and mining districts.

\begin{tabular}{lcc}
\hline Symbols & $\begin{array}{c}\text { Between South Pit and } \\
\text { North Pit }\end{array}$ & $\begin{array}{c}\text { (2) Transition from cross } \\
\text { mining to mining along } \\
\text { strike in number 3 mining } \\
\text { district in NOPM }\end{array}$ \\
\hline$\alpha$ & $25^{\circ}$ & $25^{\circ}$ \\
$\beta$ & $20^{\circ}$ & $20^{\circ}$ \\
$H$ & $258 \mathrm{~m}$ 350 $\mathrm{m}, 300 \mathrm{~m}$ on & $131 \mathrm{~m} \sim 211 \mathrm{~m}, 155 \mathrm{~m}$ on \\
$a$ & average & average \\
$A$ & $160 \mathrm{~m}$ & $100 \mathrm{~m}$ \\
$B$ & 13.23 & 19.03 \\
$l$ & 10.35 & 4.9 \\
$\gamma_{b}$ & 1250 (PHP building in the & 1150 \\
$C$ & middle part) & 1.91 \\
$\rho$ & 1.91 & 4.5811 \\
$n$ & 4.1422 & $1.5 \%$ \\
$\Delta Q$ & $1.5 \%$ & 17 \\
\hline
\end{tabular}

(2) Number 3 mining district of NOPM makes a transition from cross mining to mining along strike, and they are -168.23 and 23.50 .

In the case of $\Delta H \in(-\infty,-168.23]$ and $\Delta H \in(23.50$, $+\infty), J$ is a decreasing function, whereas, in the case of $\Delta H \in$ $(-168.23,23.50], J$ is an increasing function. Actually, within the interval $[0,211]$ and when $\Delta H=23.50, J$ reaches its maximum value.

Therefore, (1) the optimum UEWH between North Pit and South Pit is $225 \mathrm{~m}$, and (2) the optimum UEWH is $23.50 \mathrm{~m}$ for number 3 mining district of NOPM when making its transition from cross mining to mining along strike. Meanwhile, considering the restricting influence that inner dumping practice exerts on UEWH, the inner dumps need to be heightened, respectively, by over $140 \mathrm{~m}$ and $120 \mathrm{~m}$. However, the fact is that the heightening limit for inner dump is approximately the height of four dumping benches (96 m), which obviously cannot meet the uncovering requirements. According to the uncovered end wall height and length, the stripped overburden amount that cannot be internally dumped because of uncovering the end wall in the two positions mentioned above is 384.66 million $\mathrm{m}^{3}$ and 90.4 million $\mathrm{m}^{3}$, respectively. Therefore, the inner dump height in South and North mining districts should be properly enhanced. In addition, there is extra inner dumping space when the open pits in North and South districts are closed in early stage; thus overburden that needs to be transferred and dumped because of partially uncovered end wall could be properly accommodated. Results from calculations indicate that the PHP in number 3 mining district of NOPM is 48 metres high, 35 metres wide, and 792 metres long. The PHP volume is 3.357 million $\mathrm{m}^{3}$ and its shifting distance is 535 metres. Within the service scope of a single PHP, the transportation costs could be reduced by 3.55 million RMB.

\section{Conclusions}

(1) A basic principle in determining UEWH is to reduce restripping amount and the number of affected level transportation systems. It is in this principle that the troughshaped inner dumping mode with partially covered end wall has been put forward. When the restripping amounts resulting from the effect of uncovered end wall are the same, trough-shaped level uncovering mode would affect the transport systems levels on the end wall less compared with the inverted triangular mode.

(2) A mathematical model for UEWH optimization was established on the basis of minimum cost method. The model takes three factors into comprehensive consideration, namely, restripping and transferring expenses resulting from uncovered zone capacity constraint, haulage distance affected by the uncovered end wall, and transportation cost. In addition, the influence of inner dump capacity constraint on UEWH is also taken into account.

(3) Inner dumping with PHP building to connect inner dump has been put forward to reduce the influence that partially uncovered end wall practice exerts on transportation system. Based on cost compensation method and principle, equivalent one-way haulage distance should not be longer than the increased distance resulting from a truck's one-way haulage. Besides, the transportation costs saved through PHP should not be less than the restripping expenses of PHP building and backfilling. Under this circumstance, the optimization model of the PHP shifting distance is established.

(4) The paper probes into the production conditions in Huolinhe number 1 open-pit coal mine and practical situations regarding the mining district transition. An optimization analysis was made about inner dumping and UEWH. The analysis results show that optimum UEWH between South and North Pits is $225 \mathrm{~m}$ and $23.50 \mathrm{~m}$ for number 3 mining district in NOPM when making a transition from cross mining to mining along strike. However, due to limited inner dumping capacity, the height of dumping sites within South and North miming districts shall be appropriately increased. In addition, when open pits in South and North districts are closed in the early stage, it makes further room for inner dumping and would help meet the transferring demand when end wall is partially uncovered.

\section{Conflicts of Interest}

The authors declare that there are no conflicts of interest regarding the publication of this paper.

\section{Acknowledgments}

This study was supported by the Doctoral Starting Funds of Xian University of Science and Technology (2017QDJ060).

\section{References}

[1] C. S. Ji, "Study on turning method between neighboring mining panels in surface mine," Coal Engineering, vol. 43, no. 12, pp. 1-3, 2011. 
[2] Y. L. Chen, Q. X. Cai, W. Zhou, W. P. Zhang, and K. Xu, "Research on mining district change in open pit mine based on AHP," Metal Mine, vol. no. 1, pp. 51-53, 2010.

[3] Q. X. Cai and C. S. Ji, "Transition method from one mining area to the next in large surface coal mines," Journal of China University of Mining Technology, vol. 25, no. 4, pp. 45-49, 1996.

[4] M. Poros and W. Sobczyk, "Reclamation modes of the postmining terrains in the Checiny-Kielce area in the context of its use in an active geological education," Rocznik Ochrona Srodowiska, vol. 16, pp. 386-403, 2014.

[5] Z. G. Chang, K. M. Li, Y. J. Chen, T. T. Xue, and L. Ma, "Study on right angled turning box retained depth with gently inclined slope in surface mine," Coal Engineering, vol. 46, no. 7, pp. 8890, 2014.

[6] Z. H. Gu, S. G. Li, and Y. D. Zhang, "Study of remained-slope mining in surface mines with a flat-buried deposit," Journal of China University of Mining \& Technology, vol. 24, no. 2, pp. 5963, 1995.

[7] Z. G. Chang, Y. J. Chen, K. P. Duan, W. Wang, and W. L. Ren, "Research on ditch depth for triangle-coal mining in end slope covering inner dumping parallel open-pit mine," Coal Engineering, vol. 48, no. 3, pp. 15-17, 2016.

[8] R. V. Ramani, "Surface mining technology: Progress and prospects," Procedia Engineering, vol. 46, no. 3, pp. 9-21, 2012.

[9] Z. Y. Xu, Y. Q. Yang, and W. H. Xue, "Determination of reasonable position of full pressure," Opencast Mining Technology, no. 4, pp. 11-12, 1999.

[10] W. D. Han, M. Y. Gu, and X. Y. Yang, "Scheme comparison of leaving ditch in inner dump of Heidaigou open-pit," Safety in Coal Mines, vol. 45, no. 4, pp. 201-203, 2014.

[11] Z. H. Gu and Z. G. Zha, "Decision of important technological parameters for in-pit waste dump in surface mine with a flat deposit," Journal of China University of Mining \& Technology, vol. 25, no. 3, pp. 38-42, 1996.

[12] W. Zhou, Q. X. Cai, Y. P. Li, and S. Z. Chen, "Study on inner dumping covering height in large near horizontal surface mine," Coal Science and Technology, vol. 37, no. 1, pp. 53-55, 2009.

[13] J. Zhao, T. Shang, J. P. Liu, and F. M. Liu, "Inner dumping restripping volume and groove depth in near horizontal surface mine," Metal Mine, no. 2, pp. 54-56, 2012.

[14] G. Liu, P. Li, C. Li, G. Wang, R. Bai, and E. Fu, "Inner dumping covering height and repeated stripping depth of adjacent mining area in surface coal mines," Journal of Chongqing University, vol. 38, no. 6, pp. 23-30, 2015.

[15] H. L. Yu, H. Z. Zhao, W. Li, Y. F. Li, and X. S. Fang, "Application of inclined thin coal seam selective mining technology in Huolinhe South Open-pit Mine," Opencast Mining Technology, no. 9, pp. 12-14, 2015.

[16] Y. J. Liu, H. L. Yu, and H. L. Yang, "Analysis of crushing station unloading platform layout scheme of Huolinhe opencast mine," Opencast Mining Technology, no. 4, pp. 22-23, 2008. 


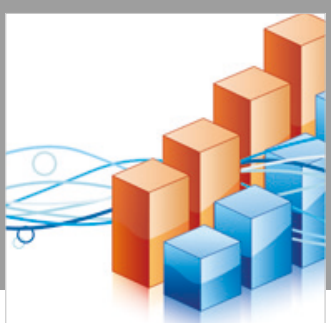

Advances in

Operations Research

\section{-n-m}
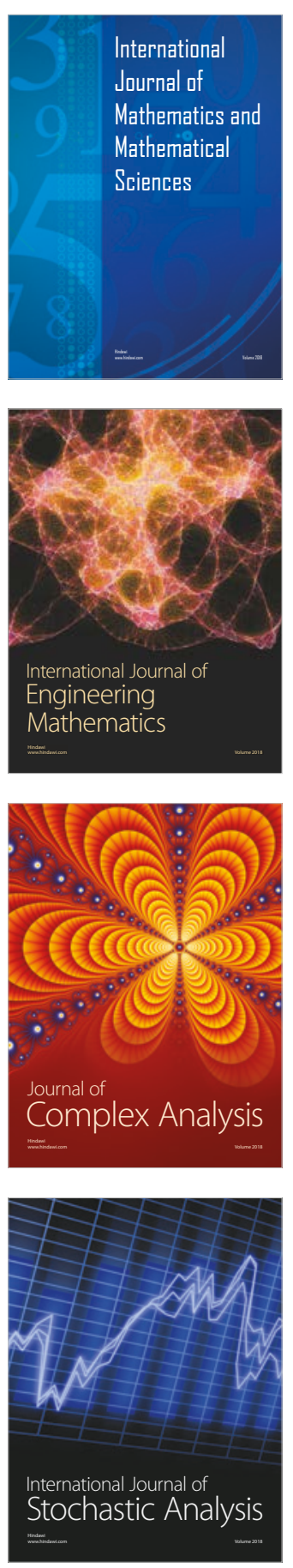
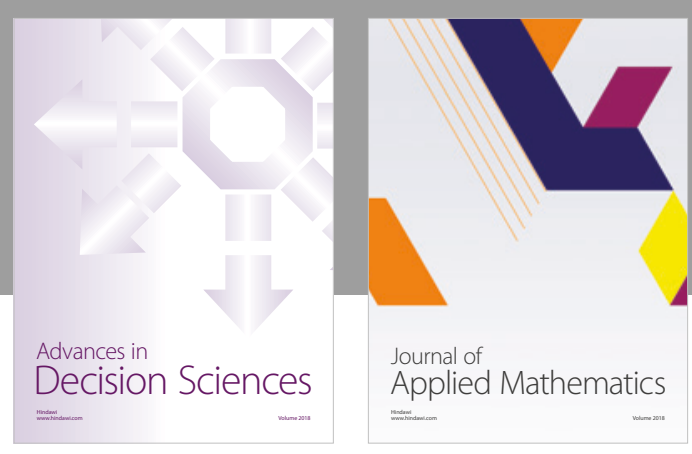

Journal of

Applied Mathematics
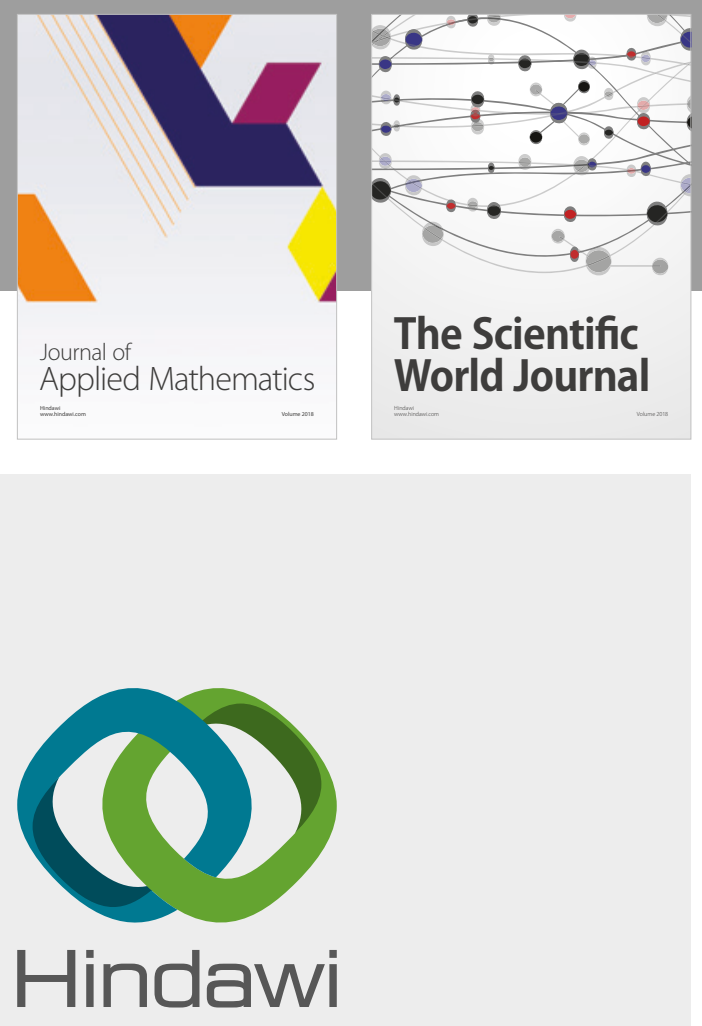

Submit your manuscripts at

www.hindawi.com

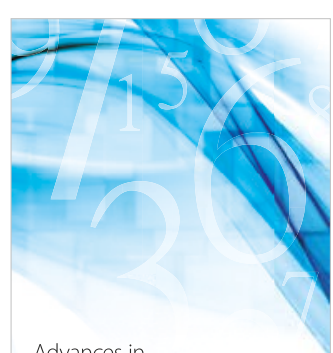

Advances in
Numerical Analysis
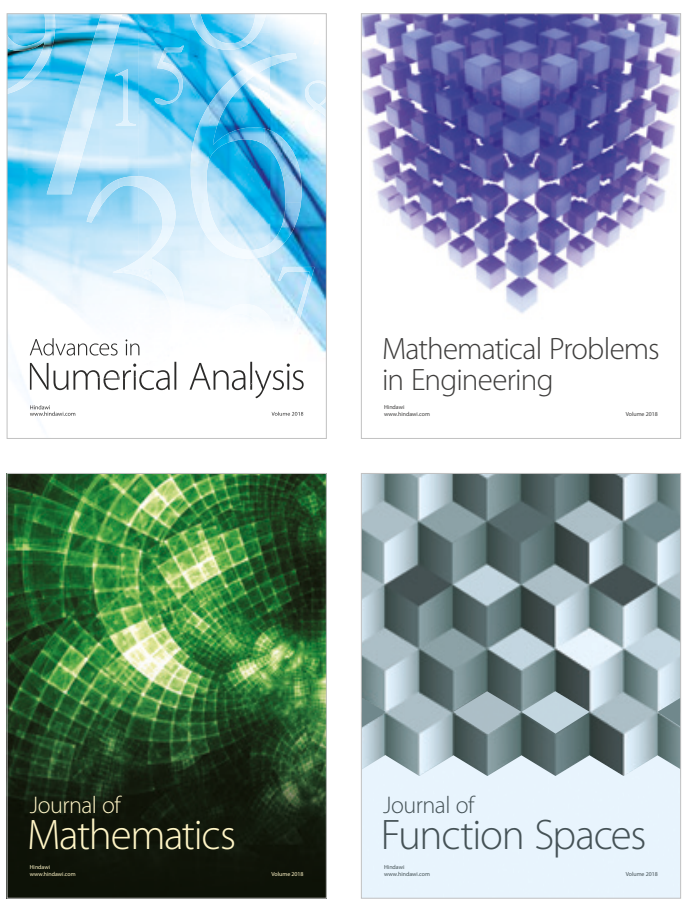

Mathematical Problems in Engineering

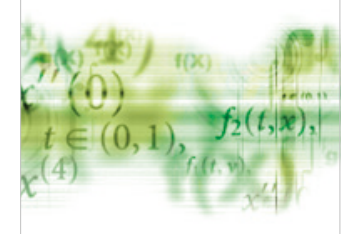

International Journal of

Differential Equations

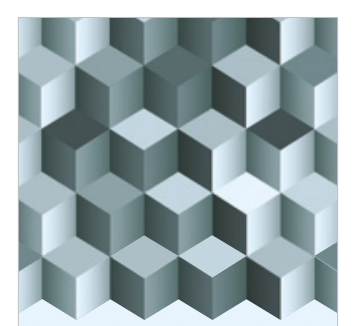

Journal of

Function Spaces

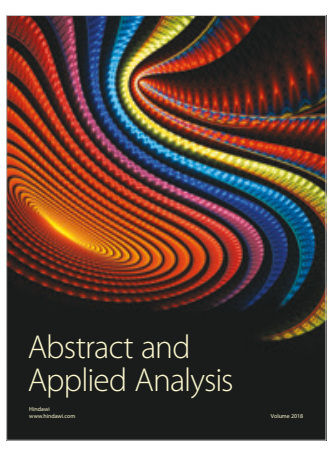

The Scientific

World Journal

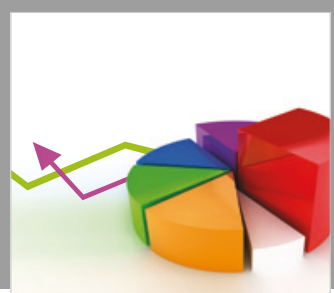

Journal of

Probability and Statistics
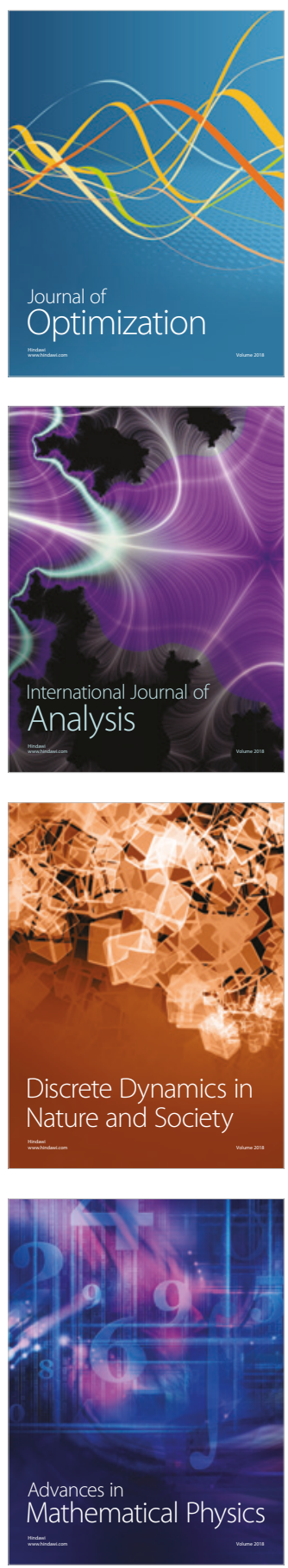